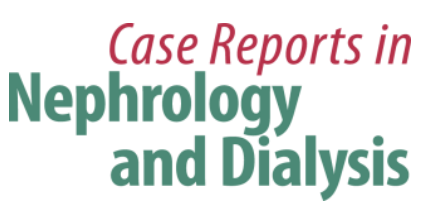

Case Rep Nephrol Dial 2017;7:63-72

DOI: 10.1159/000477663

Published online: June 23, 2017

(c) 2017 The Author(s)

Published by S. Karger AG, Basel

www.karger.com/cnd

This article is licensed under the Creative Commons Attribution-NonCommercial 4.0 International License (CC BY-NC) (http://www.karger.com/Services/OpenAccessLicense). Usage and distribution for commercial purposes requires written permission.

\title{
Hemodialysis Arteriovenous Access Occlusion Using the Amplatzer Vascular Plug in Patients with Intractable Arm Edema
}

\author{
Michele Di Filippo ${ }^{a}$ Danilo Barbarisi ${ }^{a} \quad$ Doriana Ferrara ${ }^{a}$ \\ Stefania Brancaccio ${ }^{b}$ Luca del Guercio $^{a}$ Renata Bracale ${ }^{c}$ \\ Alfredo Capuano ${ }^{b}$ Giovanni Esposito ${ }^{d} \quad$ Umberto Marcello Bracale $^{a}$ \\ ${ }^{a}$ Vascular and Endovascular Surgery Unit, Department of Public Health, University of \\ Naples Federico II, Naples, Italy; ${ }^{b}$ Nephrology Unit, Department of Public Health, \\ University of Naples Federico II, Naples, Italy; ${ }^{\mathrm{C}}$ Department of Medicine and Health \\ Science, University of Molise, Campobasso, Italy; ${ }^{d}$ Division of Cardiology, Department of \\ Advanced Biomedical Sciences, University of Naples Federico II, Naples, Italy
}

\section{Keywords}

Amplatzer vascular plug · Hemodialysis arteriovenous access · Arteriovenous fistula . Dialysis-associated steal syndrome $\cdot$ Vascular coils

\begin{abstract}
Objectives: Vascular occlusion of hemodialysis arteriovenous access (AVA) using an Amplatzer vascular plug (AVP; St. Jude Medical, St. Paul, MN, USA) is an arising and alternative practice in selected patients; however, few reported cases can be found in the literature. Herein, we report on our experience with endovascular treatment of complicated AVA. Materials and Methods: From September 2015 to December 2016, 3 patients at our clinic underwent an occlusion of hemodialysis AVA with 2 different Amplatzer vascular plugs: 2 patients with type II and 1 patient with type IV. Of these, 1 patient was treated for an autologous radiocephalic fistula, the second patient was treated for an autologous brachiocephalic fistula located at the elbow, and the third was, instead, treated for a radiocephalic forearm fistula. The reason for closing the AVA in all patients was due to the presence of dialysis-associated
\end{abstract}




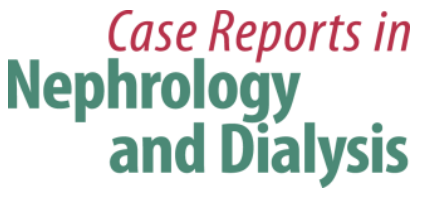

Case Rep Nephrol Dial 2017;7:63-72

DOI: $10.1159 / 000477663$

C 2017 The Author(s). Published by S. Karger AG, Basel www.karger.com/cnd

Di Filippo et al.: Hemodialysis Arteriovenous Access Occlusion Using the Amplatzer Vascular Plug in Patients with Intractable Arm Edema

steal syndrome with critical hand ischemia and intractable ipsilateral edema. Results: All AVAs were treated using an AVP. No plug migration, access revascularization, persistent ischemia, nor other complications were observed. Conclusion: This report suggests that the use of AVP for embolization of complicated AVA is a safe and reasonable alternative to open surgery in selected patients.

\section{Introduction}

The most common complications related to arteriovenous access (AVA) for hemodialysis (HD) include central venous occlusion, dialysis-associated steal syndrome (DASS), venous aneurysm with skin ulceration and nipple formation with impending rupture, critical hand ischemia, and hyperdynamic heart failure [1]. If surgical and percutaneous procedures cannot resolve AVA-related problems, it becomes necessary to close the AVA. Open surgery with fistula ligation is the most frequent treatment strategy; however, at times severe local conditions, such as swelling, edema, and ulcerations, and serious comorbidities can make this surgical approach difficult and challenging. Endovascular occlusion of the AVA with an Amplatzer vascular plug (AVP) is a viable alternative that has recently been described in the literature [2,3]. Herein, we report on the favorable results of employing this technique in 3 patients with DASS and intractable upper limb edema.

\section{Materials and Methods}

From September 2015 to December 2016, 27 patients underwent surgical or endovascular occlusion of AVA for complications related to AVA for HD; amongst these, 3 patients presented severe local conditions of the arm that made surgical treatment challenging. It was therefore decided to treat these patients by endovascular means using an AVP.

\section{Patients}

There were 2 male patients and 1 female patient; all suffered from diabetes mellitus type 2. The medium age was 63 years (range 59-68). All 3 were bearers of autologous AVA. One patient had a radiocephalic fistula, the second had a brachiocephalic fistula located at the elbow, and the third, instead, presented with a radiocephalic forearm fistula.

The AVP (St. Jude Medical, St. Paul, MN, USA) is a self-expandable, 7- to 8-mm-long, cylindrical, multi-layer nitinol mesh occluding device. The instructions for use recommend an oversizing greater than $30 \%$ with respect to the target vessel. Thanks to its radial force, the device allows firm adhesion to the vessel wall, minimizing risk of migration.

\section{Procedure}

In a dedicated operating room with a mobile fluoroscopic C-arm GE 9800 plus (General Electric, CT, USA), the patient was posed in supine position with the arm adducted. Under local anesthesia and ultrasound guidance, the cephalic or basilic vein (depending on the case) was punctured in retrograde fashion and a 5- to 7-Fr sheath introduced over a standard J-tip guidewire. On a 0.035-inch hydrophilic guidewire (Terumo, Somerset, NJ, USA) an AVP was placed and deployed next to the anastomosis. In case of complete occlusion of the AVA, coils were released. 
Patient follow-up included clinical and ultrasound evaluation at 1, 6, and 12 months from the procedures and 1 year thereafter. The mean follow-up time was 15.7 months (range 12-24).

\section{Results}

Technical success was achieved in 2 of the patients with only 1 AVP and in the third case by additional deployment of coils after AVP. All 3 patients showed complete occlusion of AVA within 20 min. Complete resolution of ischemic symptoms and arm edema was observed in all patients at the 1-month follow-up. At a following evaluation, device-related complications, such as AVP migration or AVA recanalization, were not reported.

Case 1

A 63-year-old male patient suffering from diabetes mellitus type 2, peripheral artery disease, chronic hepatitis HCV+, and chronic kidney disease was in HD through a left radiocephalic AVA since 2013. In January 2015, the patient presented DASS with severe swelling. At a duplex scan, the presence of high-flow tributaries several centimeters beyond the anastomosis was observed. We decided to close the AVA deploying an AVP type IV (6 $\times 11 \mathrm{~mm})$ in the cephalic vein (Fig. 1). Within a few minutes, the complete occlusion of the vessel was obtained (Fig. 2).

\section{Case 2}

A 59-year-old female affected by severe hypertension had undergone kidney transplantation in 2005. Because of chronic rejection, a distal radiocephalic AVA on the left forearm was performed. In March 2016, the patient showed upper left limb swelling and ischemic ulcerations on the right forearm (Fig. 3). The preoperative duplex scan investigation showed the presence of a tributary vein beyond the anastomosis. Due to the severe local conditions, our team ruled out an open approach to close the AVA. In this case, an AVP type IV $(7 \times 12.5$ $\mathrm{mm}$ ) was placed in the cephalic vein, close to the anastomosis (Fig. 4). The following examinations showed complete occlusion of the AVA and resolution of ulcers and arm edema after 3 months (Fig. 5, Fig. 6).

Case 3

A 68-year-old male heavy smoker with hypertension, ischemic heart disease, pulmonary emphysema, diabetes mellitus type 2 , and chronic kidney disease requiring HD through a brachiocephalic left AVA since 2012 came to our attention in August 2016 complaining about severe edema and multiple trophic lesions on his left forearm and hand (Fig. 7). The contrast-enhanced CT scan showed bilateral thrombosis of the innominate vein involving the superior vena cava. We decided to occlude the AVA through an AVP type II $(14 \times 20 \mathrm{~mm})$. In order to achieve complete occlusion of the vein, deployment of an additional coil was required (16 × 40 mm, Concerto; Covidien, Irvine, CA, USA) (Fig. 8).

Subsequent clinical and instrumental examinations confirmed the complete occlusion of the AVA and the resolution of the upper limb ischemia (Fig. 9, Fig. 10). Moreover, this patient underwent a right brachiobasilic AVA following endovascular recanalization of the right innominate vein with a covered stent. 


\section{Case Reports in Nephrology and Dialysis}

\section{Discussion}

In Italy today, 44,000 patients with chronic kidney failure undergo HD treatment by AVA [4]. The most common AVAs are autologous radiocephalic, brachiocephalic, and brachiobasilic. Several complications are related to AVA, such as central venous occlusion, DASS, venous aneurysm with skin ulceration and nipple formation, critical hand ischemia, and hyperdynamic heart failure.

DASS occurs in 1.6-8\% of the patients with arteriovenous fistula for HD [1]. The syndrome is more common in AVA located close to the elbow than in distal ones. At its onset, DASS is characterized by asthenia and pallor of the affected upper limb and subsequently develops into severe ischemia with paresthesia, hypothermia, ulcerations, and loss of tissue. A preoperative evaluation cannot anticipate the risk of steal syndrome, although diabetes mellitus and previous surgical access are important risk factors [5]. The diagnosis is clinical, followed by a duplex scan and then an angiography (second-level instrumental exam) [6].

Surgical ligation of AVA is indeed a definitive treatment. Therefore, in patients with DASS and without contraindications to surgical treatment, ligation is the gold standard procedure. Many patients cannot undergo surgical treatment due to adverse local conditions (swelling, edema, and ulcerations) or serious comorbidities, and therefore, in selected patients, endovascular occlusion with AVP potentially associated with coils is a feasible and effective treatment [7].

Powell et al. [8] reported on 7 patients with complicated HD access who were treated with AVP. Their complex venous anatomy, wound healing, and severe local conditions made surgical ligation challenging. The reasons for closing the AVA were the presence of DASS, high flow tributaries, and limb swelling. All patients presented immediate technical success without complications at the 3-month follow-up.

Gumus [9] confirmed these results in his description of 21 patients who had undergone endovascular occlusion of arteriovenous fistula with AVP. The indication for embolization of fistulas included hyperdynamic heart failure, central venous occlusion, venous aneurysm with skin ulceration, DASS, and critical hand ischemia. The reported rate of technical success was $100 \%$. No complications related to the procedure were observed at the 1 -year follow-up.

Bourquelot et al. [10] reported on 20 AVP deployments in 19 patients (14 occlusions and 6 flow reductions). Indications for occlusion included central vein occlusion, high flow, hand ischemia, successful kidney transplant, and AVA superficialization technical failure. A flow reduction was performed for well-tolerated high flow or high flow with distal ischemia. Technical success, with complete occlusion of AVA, was achieved in all patients. Due to persisting ischemic symptoms, surgical revascularization was necessary in only 1 patient. No plug migration was observed.

In cases of incomplete occlusion of AVA after AVP deployment, several authors reported the use of coils for a safer and more accurate occlusion of arteriovenous fistula, with a greater rate of technical success $[11,12]$. However, deployment of coils only increases the risk of device migration. 


\section{Conclusion}

Our experience leads us to assert that in select patients the AVP is a safe and feasible technique employed to occlude AVA for HD, without precluding additional deployment of coils if needed to complete occlusion.

\section{Statement of Ethics}

Consent for publication was obtained from all patients.

\section{Disclosure Statement}

The authors have no conflicts of interest to declare.

\section{References}

-1 Bracale UM, Crescenzi C, Narese D, Giribono AM, Viviani E, Ferrara D, Caioni F, Midiri M, Vitale G, del Guercio L: Management of finger gangrene caused by steal syndrome in vascular access for hemodialysis. Personal experience and a brief review of the literature. Ann Ital Chir 2015;86:239-245.

-2 Bui JT, Knuttinen MG, West DL, Owens CA: Amplatzer vascular plug for arteriovenous hemodialysis access occlusion: initial experience. J Vasc Access 2009;10:5-10.

-3 Bracale UM, Porcellini M, del Guercio L, Bracale G: Embolization of a symptomatic pseudoaneurysm developing after transplant nephrectomy. Intern Med 2013;52:291-292.

-4 Gessaroli M, Alessi Innocenti A, Carbonari L, De Donato G, Dorigo W, Iob G, Morelli I, Parente B: Linee guida SICVE: accessi vascolari. Ital J Vasc Endovasc Surg 2015;22:95-116.

5 Tynan-Cuisinier GS, Berman SS: Strategies for predicting and treating access induced ischemic steal syndrome. Eur J Vasc Endovasc Surg 2006;32:309-315.

6 Goff CD, Bloch PH, DeMasi RJ, Gregory RT, Gayle RG, Parent FN, Meier GH, Wheeler JR: Steal syndrome complicating hemodialysis access procedures: can it be predicted? Ann Vasc Surg 2000;14:138-144.

7 Bozkurt AK, Kasapoglu B, Teber MA: Use of the Amplatzer type 2 plug for flow redirection in failing autogenous hemodialysis fistulae. Cardiovasc Intervent Radiol 2015;38:887-893.

-8 Powell SN, Odetoyinbo T, Littler P, Oweis D, Sharma A, Bakran A: Early experience with the Amplatzer vascular plug II for occlusive purposes in arteriovenous hemodialysis access. Cardiovasc Intervent Radiol 2010;33:150-156.

$\$ 9$ Gumus B: Percutaneous embolization of hemodialysis fistulas by Amplatzer vascular plug with midterm follow-up. J Vasc Interv Radiol 2011;22:1581-1585.

-10 Bourquelot PK, Raynaud A, Beyssen B, Ricco JB: Amplatzer vascular plug for occlusion or flow reduction of hemodialysis arteriovenous access. J Vasc Surg 2014;59:260-263.

-11 Owens CA, West DL, Sepahdari A: Use of the Amplatzer vascular plug as a coil constrainer during endovascular occlusion of a dialysis shunt. Cardiovasc Intervent Radiol 2007;30:754-756.

$\$ 12$ Ozyer UH, Aytekin C, Boyvat F, Karakayali F: Application of the Amplatzer vascular plug in endovascular occlusion of dialysis accesses. Cardiovasc Intervent Radiol 2009;32:967-973. 


\section{Case Reports in Nephrology and Dialysis}

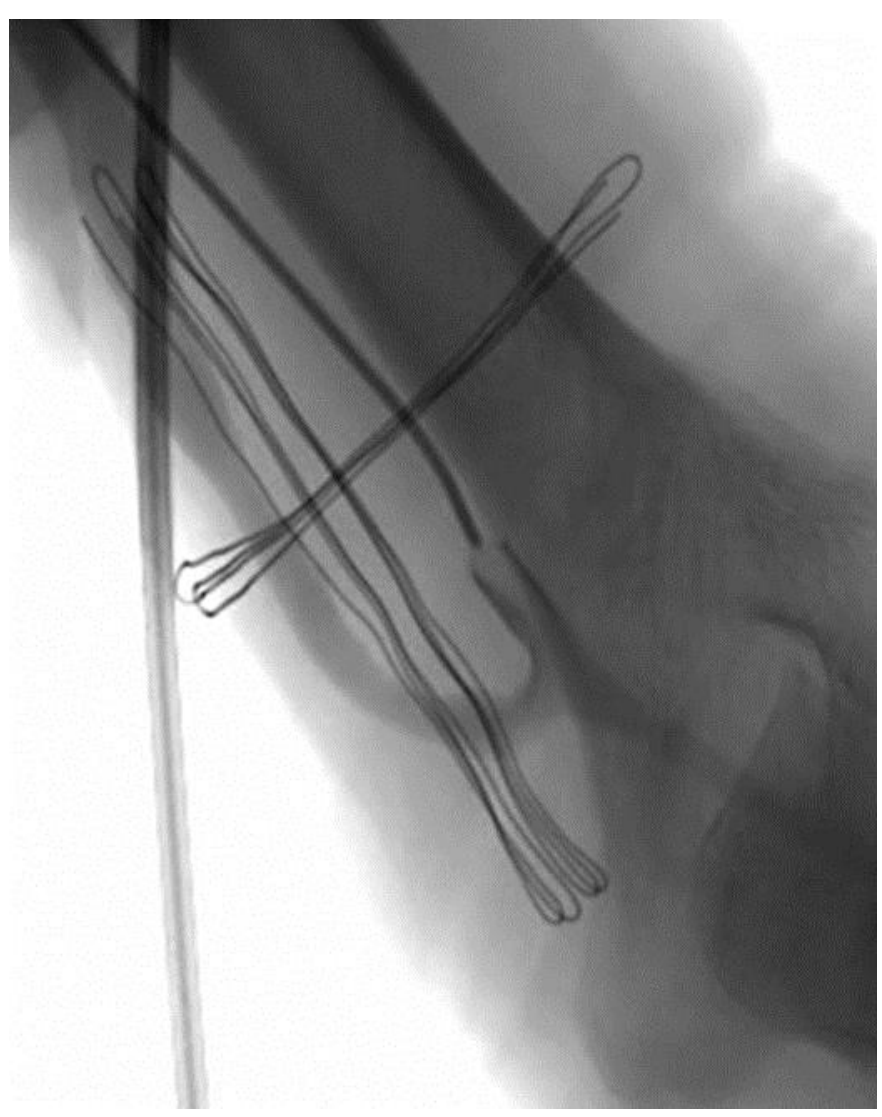

Fig. 1. Selective angiogram before treatment. 


\section{Case Reports in Nephrology and Dialysis}

Case Rep Nephrol Dial 2017;7:63-72 DOI: $10.1159 / 000477663$ (c) 2017 www.karger.com/cnd

Di Filippo et al: Hemodialysis Arteriovenous Access Occlusion Using the Amplatze Vascular Plug in Patients with Intractable Arm Edema

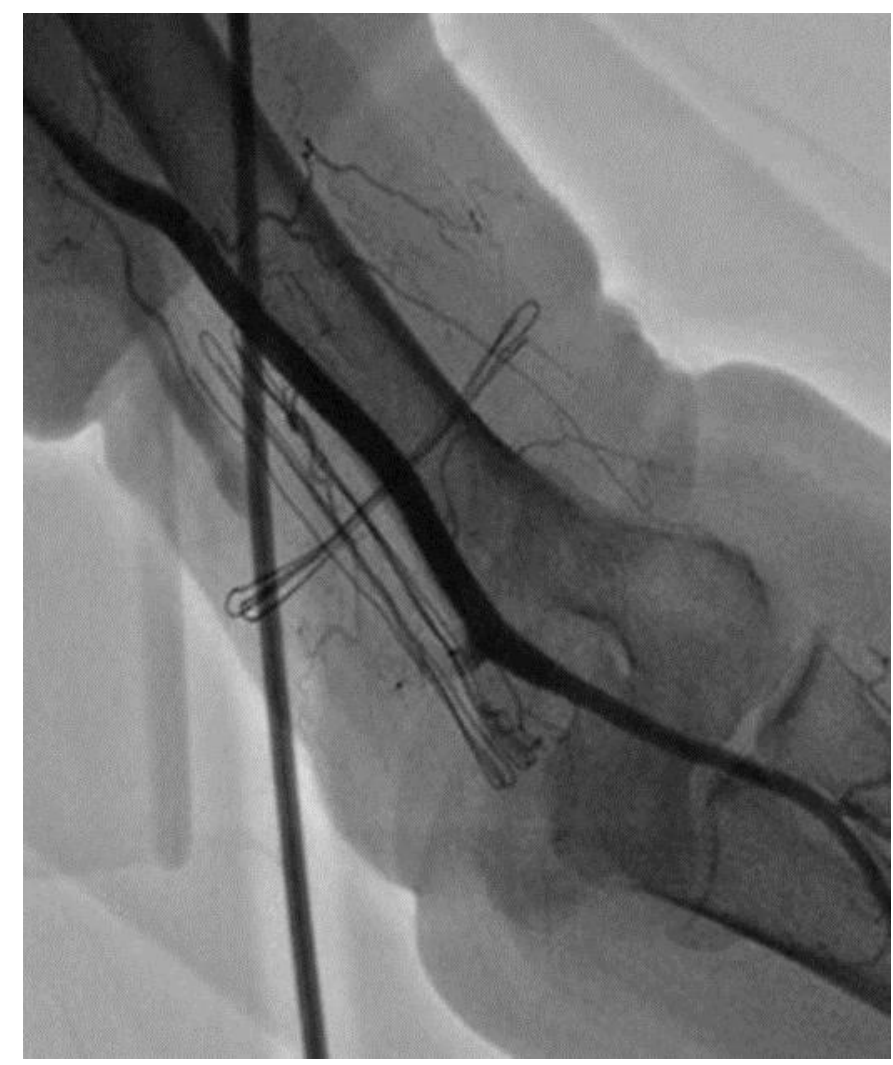

Fig. 2. Completion angiogram after deployment of AVP in the cephalic vein.

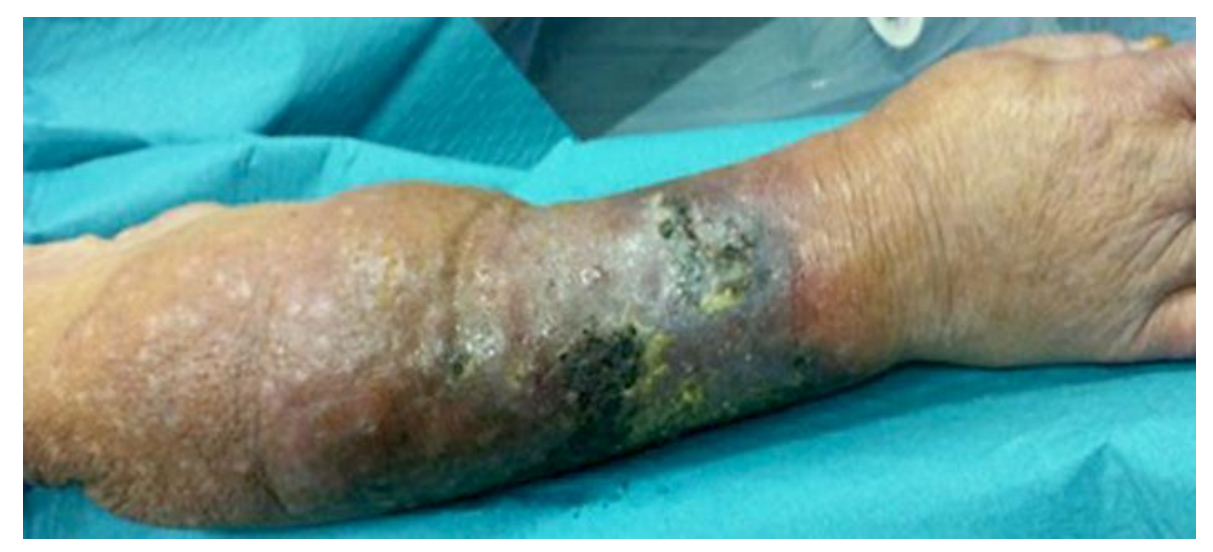

Fig. 3. Upper limb swelling and ischemic ulceration on the left forearm before AVA closure. 


\section{Case Reports in \\ Nephrology and Dialysis}

Case Rep Nephrol Dial 2017;7:63-72

DOI: $10.1159 / 000477663$

(c) 2017 The Author(s). Published by S. Karger AG, Basel www.karger.com/cnd

Di Filippo et al.: Hemodialysis Arteriovenous Access Occlusion Using the Amplatze Vascular Plug in Patients with Intractable Arm Edema

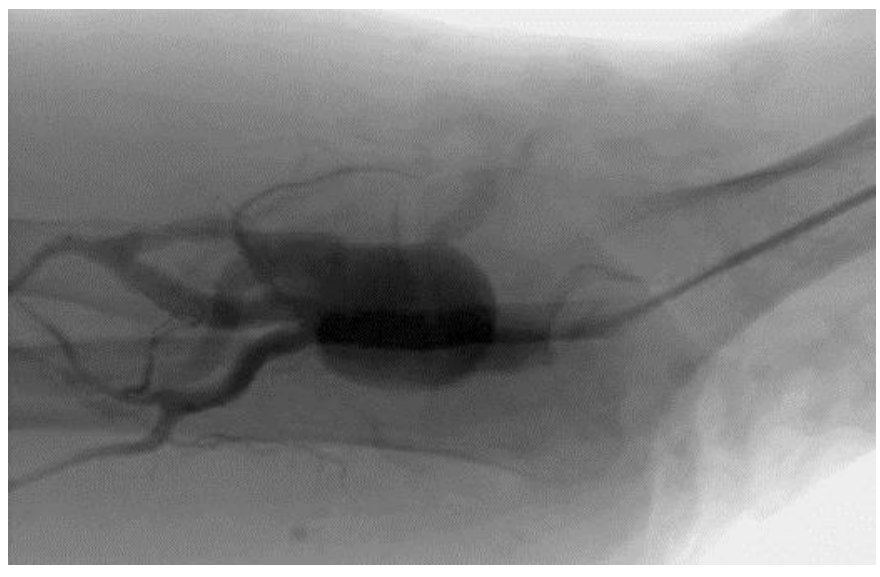

Fig. 4. Selective angiogram before treatment.

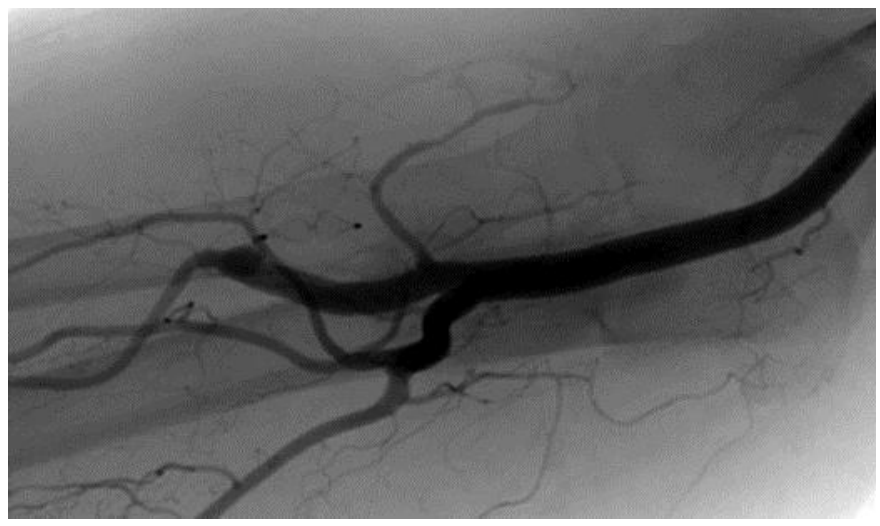

Fig. 5. Completion angiogram after AVP IV deployment close to the anastomosis.

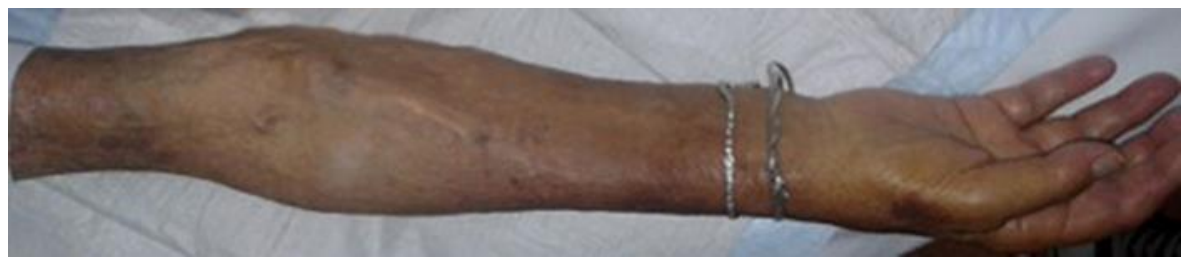

Fig. 6. Upper limb at 3 months after the endovascular treatment. 


\section{Case Reports in \\ Nephrology and Dialysis}

Case Rep Nephrol Dial 2017;7:63-72

DOI: $10.1159 / 000477663$

c 2017 The Author(s). Published by S. Karger AG, Basel www.karger.com/cnd

Di Filippo et al.: Hemodialysis Arteriovenous Access Occlusion Using the Amplatze Vascular Plug in Patients with Intractable Arm Edema

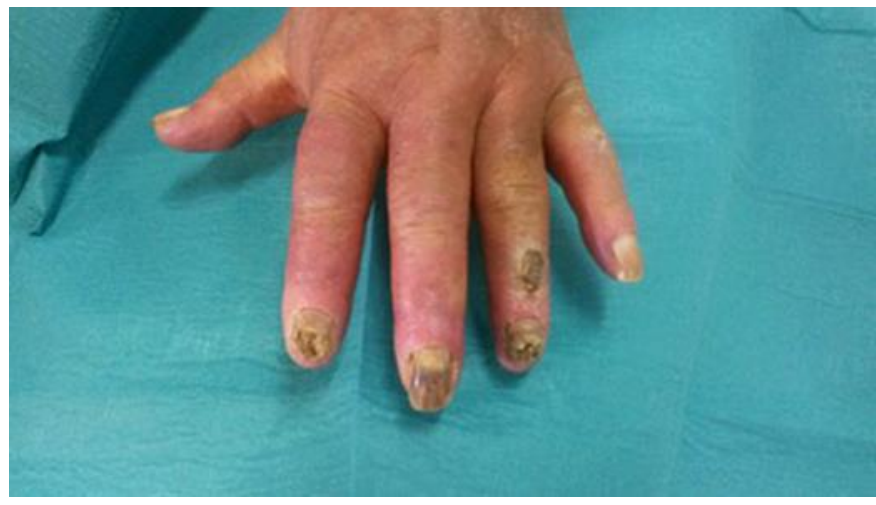

Fig. 7. Ischemic lesions and swelling of the left hand before treatment.

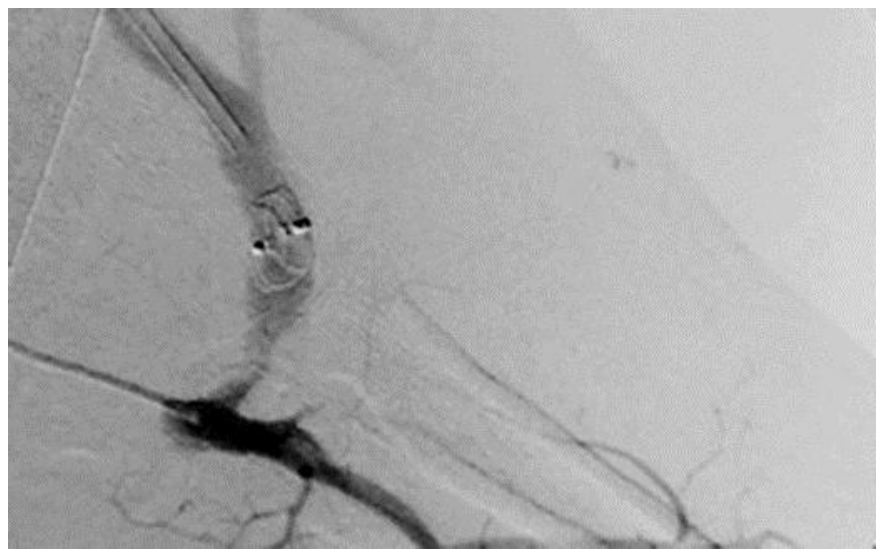

Fig. 8. AVP II deployment.

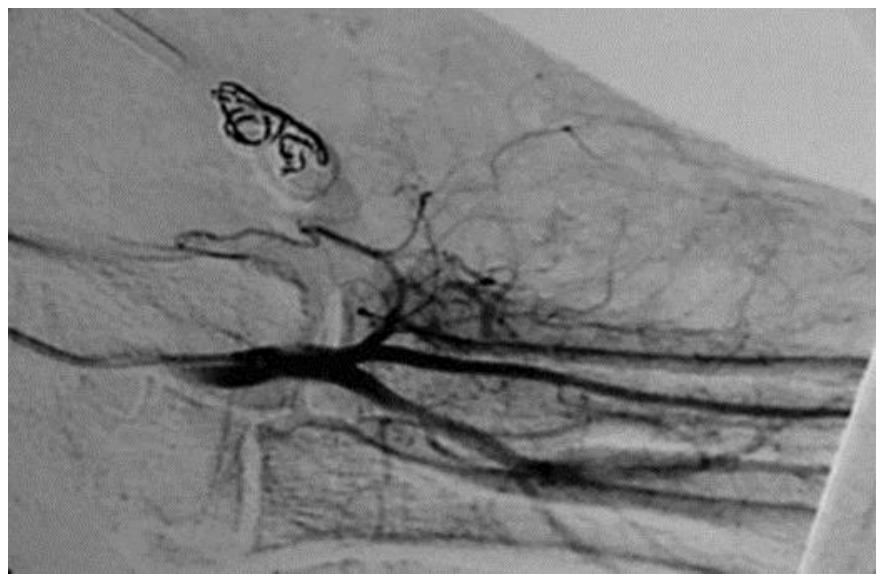

Fig. 9. Deployment of an additional coil to obtain complete AVA occlusion. 


\section{Case Reports in Nephrology and Dialysis}

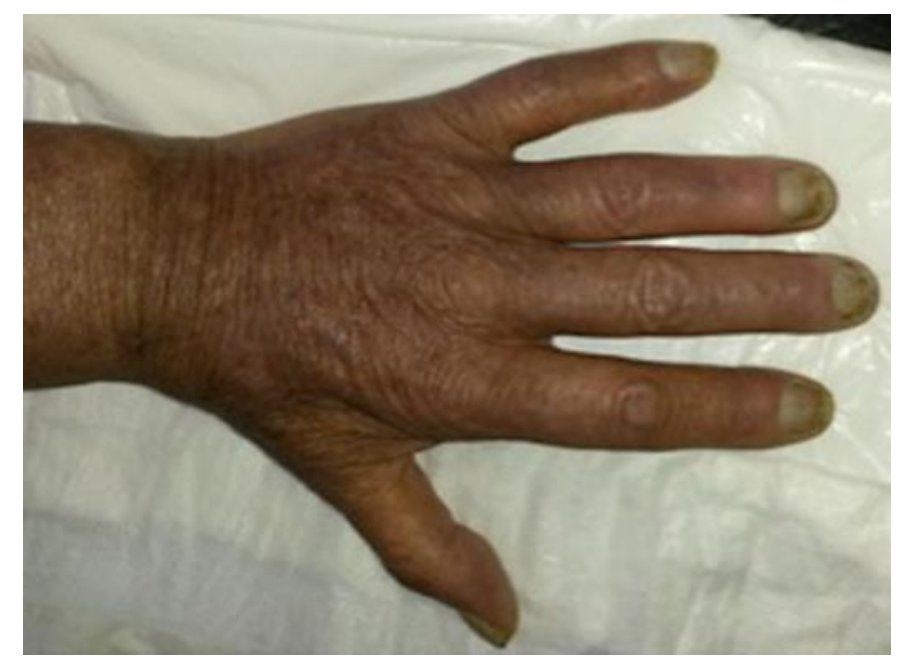

(c) 2017 The Author(s). Published by S. Karger AG, Basel DOI: 10.1159/000477663 www.karger.com/cnd

Di Filippo et al:: Hemodialysis Arteriovenous Access Occlusion Using the Amplatzer Vascular Plug in Patients with Intractable Arm Edema

Fig. 10. Clinical healing of the lesions 6 months after the endovascular procedure. 